\title{
ANTIBIOTIC RESISTANCE IN CSOM IN A TEACHING HOSPITAL
}

\author{
Rangaineni Bharatha Sena1, Gandham Pavani²
}

1 MBBS Student, Department of Microbiology, Apollo Institute of Medical Sciences, Hyderabad.

${ }^{2}$ Associate Professor, Department of Microbiology, Apollo Institute of Medical Sciences, Hyderabad.

\section{ABSTRACT}

\section{BACKGROUND}

Antibiotic resistance pattern of CSOM has been changing according to geographical variation and differences in patient population. Increased and irrational use of broad spectrum antibiotics, as well as resistance in bacterial isolates, has become very common. Staphylococcus is one of the most important bacteria in CSOM and MRSA is a common pathogen in otologic diseases. Continuous and periodic surveillance of MRSA is necessary to reduce the spread of antibiotic resistant pathogens in CSOM cases.

\section{OBJECTIVES}

To identify the bacteria causing CSOM, to determine the antibiotic resistance of the isolates from CSOM samples and also to determine the methicillin resistance of the isolates.

\section{MATERIALS AND METHODS}

Prospective study of 30 samples from clinically suspected cases of CSOM was performed over a period of two months. Samples were processed by microscopy and culture and the culture isolates were identified by standard biochemical reactions. Antibiotic susceptibility test of the isolates was performed as per CLSI guidelines.

\section{RESULTS}

$73.33 \%$ of the isolates were Staphylococcus aureus. $26.66 \%$ of the isolates were Enterococcus. $100 \%$ resistance to Cotrimoxazole, Ampicillin sulbactam, Azithromycin, Cefuroxime, Cefazolin, Doxycycline, Tetracycline and Cefepime was observed followed by $50 \%$ resistance to Amikacin and 43.3\% resistance to Amoxiclav and Ceftazidime. MRSA constituted 50\% of the total isolates.

\section{CONCLUSION}

Cotrimoxazole, Ampicillin sulbactam, Azithromycin, Cefuroxime, Cefazolin, Doxycycline, Tetracycline and Cefepime should not be considered for treatment of CSOM in our hospital area. There is an over use of Cefepime and Ceftazidime in our hospital area. Increased isolation of MRSA warrants potential interventions to reduce the prevalence of MRSA in our hospital area.

\section{KEYWORDS}

CSOM, Antimicrobial Resistance, Methicillin Resistance.

HOW TO CITE THIS ARTICLE: Sena RB, Pavani G. Antibiotic resistance in CSOM in a teaching hospital. J. Evolution Med. Dent. Sci. 2016;5(61):4263-4267, DOI: 10.14260/jemds/2016/973

\section{INTRODUCTION}

Chronic Suppurative Otitis Media (CSOM) is a common disease of childhood. It is a persistent or intermittent infection of ear for more than three months' duration. There is purulent or mucopurulent discharge through the perforated tympanic membrane. Causative micro-organism may be bacteria, fungi and virus resulting in inflammation of mucosal lining of middle ear. If not treated it leads to partial or total loss of the tympanic membrane and ossicles resulting in acquired hearing loss. It is a highly prevalent condition and an important cause of preventable hearing loss. Chronic Suppurative Otitis Media (CSOM) has assumed world-wide importance. In the developing countries, it has continued to constitute a heavy disease burden with the prevalence of

Financial or Other, Competing Interest: None.

Submission 06-06-2016, Peer Review 18-07-2016,

Acceptance 23-07-2016, Published 30-07-2016.

Corresponding Author:

Gandham Pavani,

Associate Professor

Department of Microbiology,

Apollo Institute of Medical Sciences and Research,

Jubilee Hills, Hyderabad-500096,

Telangana.

E-mail:drpavanic@gmail.com

DOI: $10.14260 /$ jemds/2016/973 chronic ear infections being up to 72 cases per 1000 inhabitants.

According to a classification by World Health Organization (WHO) for burden of CSOM, India has been placed in highest $(>4 \%)$ prevalence group. ${ }^{1}$ Several organisms have been implicated in the causation of CSOM, posing a challenge to the management. Commonly isolated bacteria include Staphylococcus aureus (Methicillin-resistant [MRSA] and methicillin-sensitive [MSSA]), Pseudomonas, Proteus, Coagulase-negative staphylococci, Enterococcus, and Anaerobes (Including Peptostreptococcus, Fusobacterium, Prevotella and Porphyromonas). ${ }^{2}$ Polymicrobial growth is common. ${ }^{3}$ With the emergence of antibiotic resistance as well as the ototoxicity of antibiotics and the potential risks of surgery, there is an urgent need to develop effective therapeutic strategies against CSOM. ${ }^{2}$ The indiscriminate and haphazard use of antibiotics in CSOM have resulted in persistence of low-grade infections. Further the changes in the microbiological flora with the advent of new antimicrobials made the evaluation of bacterial flora of CSOM and their antibiotic resistance pattern very important. This evaluation will contribute to rational usage of antibiotics, success of treatment and prevention of the complications in CSOM patients. ${ }^{4}$ Often, the primary care physicians are usually the first to see these patients and mostly rely on 
empirical antibiotic therapy and only refer to the otolaryngologist when their treatments fail. Due to the recurrent nature of CSOM and the development of resistant pathogenic organisms, control of infection poses a greatest therapeutic challenge. The challenges of resistance have even been compounded by the activities of quacks where they engage in uninformed administration of antibiotics to these patients. ${ }^{5}$ Hence, the present study was conducted to detect the antibiotic resistance pattern of the isolates of CSOM in our hospital area. Identification and detection of MRSA is also important before treatment of CSOM cases, as cases with these infections are resistant to routine beta-lactam antibiotics and Penicillin. ${ }^{6}$ Moreover, empirical antibiotic treatment of patients with antibiotic-resistant bacteria such as methicillin-resistant Staphylococcus aureus (MRSA), which have been increasingly identified in infectious diseases may result in treatment failure or complications. ${ }^{7}$ Knowledge of local bacteriological pattern and their antibiotic resistance is essential for effective and low cost treatment.

\section{MATERIALS AND METHODS}

A prospective study of 30 patients with clinical evidence of CSOM attending the Outpatient Department of Apollo General Hospital, Jubilee Hills, Hyderabad, was done for a period of 2 months from April to June 2015. The processing of the samples was done in the Microbiology Department of AIMSR. Institutional Ethics Committee approval was obtained for the study. Patients of all ages and either gender suffering from CSOM as determined by otoscopic examination were included in the study. Patients with current febrile illness, antibiotic usage in the preceding 2 weeks, ear surgery or any other relevant ear problems were excluded from the study. Two sterile swabs were used to collect ear discharge from each patient. The first swab was used to make a smear on a clean, grease-free slide for preliminary differentiation of bacteria by Gram staining. The second swab was plated on $5 \%$ blood agar, MacConkey's agar and chocolate agar and the plates incubated at $37^{\circ} \mathrm{C}$ for 48 hours, after which a part of the colony is picked up with a sterile loop for making a smear. The smear was stained by Gram staining again and findings recorded. 4 The bacterial colonies isolated in culture were identified by standard biochemical reactions. Antibiotic susceptibility testing is done by modified Kirby-Bauer disc diffusion technique using Mueller-Hinton agar as per CLSI guidelines. Pure colonies of the isolates were suspended in sterile normal saline and the turbidity of the suspension adjusted to $0.5 \mathrm{McF}$ arland standard. A sterile cotton swab was dipped into the suspension and squeezed against the side of the bottle and then used to inoculate a Mueller-Hinton agar before the application of antibiotic discs and subsequently incubated at $37^{\circ} \mathrm{C}$ for $18-24$ hours. The standard antibiotic discs as recommended by CLSI guideline were used. The antibiotics used were Ampicillin sulbactam $(10 \mu \mathrm{g})$, Amoxiclav (30 $\mu \mathrm{g})$, Ciprofloxacin (5 $\mu \mathrm{g})$, Ofloxacin $(5 \mu \mathrm{g})$, Vancomycin $(30 \mu \mathrm{g})$, Cefazolin $(30 \mu \mathrm{g})$, Cefotaxime (30 $\mu \mathrm{g})$, Ceftazidime (30 $\mu \mathrm{g})$, Netilmicin (30 $\mu \mathrm{g})$, Chloramphenicol (30 $\mu \mathrm{g})$, Amikacin $(30 \mu \mathrm{g})$, Doxycycline $(30 \mu \mathrm{g})$, Tetracycline (30 $\mu \mathrm{g})$, Cotrimoxazole $(1.25+23.75 \mu \mathrm{g})$, Azithromycin $(15 \mu \mathrm{g})$, Ceftriaxone $(30 \mu \mathrm{g})$, Cefuroxime $(30 \mu \mathrm{g})$ and Cefepime (30 $\mu \mathrm{g})$. Results of the antibiotic susceptibility test were interpreted and antibiotic resistance of the isolates determined in accordance with Clinical and Laboratory Standards Institute Guidelines. Reference strains such as $S$. aureus ATCC 25923 and Enterococcus faecalis ATCC 29212 were used for quality control for antibiotic susceptibility testing. Detection of methicillin resistance in staphylococcal isolates was done by cefoxitin disc method as per CLSI guidelines. ${ }^{8}$

All dehydrated media, reagents and antibiotic discs were procured from Hi-Media Laboratories Pvt. Ltd., Mumbai, India.

\section{RESULTS}

A total of 30 ear swabs from cases of CSOM were studied to identify the bacterial agents causing CSOM and to determine the antibiotic resistance of these isolates. Out of the 30 samples of CSOM processed, Staphylococcus aureus was isolated from $22(73.33 \%)$ of the isolates. Enterococcus was isolated from $8(26.66 \%)$ of the isolates.

\begin{tabular}{|c|c|c|}
\hline Organism & $\begin{array}{c}\text { No. of } \\
\text { Cases }\end{array}$ & $\begin{array}{c}\text { Percentage of } \\
\text { Cases }\end{array}$ \\
\hline $\begin{array}{c}\text { Staphylococcus } \\
\text { aureus }\end{array}$ & 22 & $73.3 \%$ \\
\hline Enterococci & 8 & $26.6 \%$ \\
\hline \multicolumn{2}{|c|}{ Table 1: Organisms Isolated in CSOM Cases } \\
\hline
\end{tabular}

When the antibiotic resistance of the isolates in our study was analysed, highest degree of resistance (100\%) to Cotrimoxazole, Ampicillin sulbactam, Azithromycin, Cefuroxime, Cefazolin, Doxycycline, Tetracycline and Cefepime was observed. Isolates also showed increased resistance to Amikacin (50\%), Amoxiclav (43.3\%) and Ceftazidime (43.3\%). Table 1 shows the antibiotic resistance of the isolates and Table 2 shows the methicillin resistance of the isolates.

\begin{tabular}{|c|c|}
\hline Antibiotic & No. (\%) of Resistant Isolates \\
\hline Ampicillin sulbactam & $30(100 \%)$ \\
\hline Amoxiclav & $13(43.3 \%)$ \\
\hline Ciprofloxacin & $0(0 \%)$ \\
\hline Ofloxacin & $0(0 \%)$ \\
\hline Vancomycin & $12(40 \%)$ \\
\hline Cefazolin & $30(100 \%)$ \\
\hline Cefotaxime & $7(23.3 \%)$ \\
\hline Ceftazidime & $13(43.3 \%)$ \\
\hline Netilmicin & $0(0 \%)$ \\
\hline Chloramphenicol & $12(40 \%)$ \\
\hline Amikacin & $15(50 \%)$ \\
\hline Doxycycline & $30(100 \%)$ \\
\hline Tetracycline & $30(100 \%)$ \\
\hline Cotrimoxazole & $30(100 \%)$ \\
\hline Azithromycin & $30(100 \%)$ \\
\hline Ceftriaxone & $7(23.3 \%)$ \\
\hline Cefuroxime & $30(100 \%)$ \\
\hline Cefepime & $30(100 \%)$ \\
\hline \multicolumn{2}{|c|}{ Table 2: Antibiotic Resistance of the Isolates } \\
\hline
\end{tabular}




\begin{tabular}{|c|c|c|c|c|}
\hline $\begin{array}{l}\text { No. of } \\
\text { Staphylococcus } \\
\text { aureus Isolates }\end{array}$ & $\begin{array}{c}\text { No. of MSSA } \\
\text { Isolates among Staphylo- } \\
\text { coccus } \\
\text { aureus } \\
\text { Isolates }\end{array}$ & $\begin{array}{c}\text { \% of MSSA } \\
\text { Isolates } \\
\text { among Staphylo } \\
\text { coccus } \\
\text { aureus } \\
\text { Isolates }\end{array}$ & $\begin{array}{c}\text { No. of } \\
\text { MRSA Isolates among } \\
\text { Staphylococcus } \\
\text { aureus } \\
\text { Isolates }\end{array}$ & $\begin{array}{c}\text { \% of MRSA } \\
\text { Isolates } \\
\text { among Staphylo } \\
\text { coccus } \\
\text { aureus } \\
\text { Isolates }\end{array}$ \\
\hline 22 & 7 & $31.3 \%$ & 15 & $68.2 \%$ \\
\hline
\end{tabular}

When methicillin resistance of the staphylococcal isolates was analysed, $68.2 \%$ of the staphylococcal isolates were MRSA and $31.3 \%$ were MSSA.

\section{DISCUSSION}

Among the 30 samples of CSOM processed, Staphylococcus aureus was isolated from $22(73.33 \%)$ of the isolates. Enterococcus was isolated from $8(26.66 \%)$ of the isolates. Predominant bacterial aetiology of CSOM in this region is Staphylococcus aureus (73.3\%). In contrast, other studies from India. ${ }^{9}$ revealed about $16 \%$ isolation of staphylococcus, a study from Nigeria revealed $13.5 \%$ Staphylococcus aureus. ${ }^{10}$ and another from Pakistan. ${ }^{11}$ revealed $41.5 \%$ Staphylococcus aureus. All these studies showed a different trend in which Pseudomonas was the most prevalent organism and this could be due to the variation in micro-organisms in different regions and effect of climate. However, Pseudomonas does not usually inhabit the upper respiratory tract and it probably gains access to the middle ear through a defect in the tympanic membrane. It is usually a secondary invader. ${ }^{3}$ Since Staphylococcus aureus is the predominant isolate in our study and it being a primary pathogen in CSOM, CSOM in our hospital area can be considered as a primary infection.

A study from South India (Coastal AP).12 revealed Pseudomonas as the predominant organism. In a study conducted in hot and dry regions of AP.13 Staphylococcus aureus was the major isolate. Our place being a relatively dry place and the predominant isolate in our study being Staphylococcus aureus, it can be concluded that Staphylococcus aureus is the predominant pathogen of CSOM in the dry and less humid regions.

In the present study, Enterococcus sp. were isolated in $26.6 \%$ cases. Other workers who had isolated Enterococci in CSOM are Hiremath et al (2001). ${ }^{14}$ in $0.79 \%$ cases and Loy et al (2002) in $2.2 \%$ cases. 15 There is an increased isolation of Enterococci in our study compared to the previous studies conducted by Hiremath et al and Loy et al. From this we conclude that Enterococci, generally regarded as normal flora of gastrointestinal and genitourinary tract of humans, is emerging as the etiogen of several nosocomial as well community-acquired infections since last two decades.

In the era of antibiotics, the emergence of antibiotic resistance is becoming more common. Patient non-compliance is an important factor responsible for the development of antibiotic resistance. As soon as symptoms subside, many patients stop taking antibiotics before completion of therapy and allow partially resistant microbes to flourish. Such practice should be condemned strongly and patients should be educated to avoid the same for the antibiotics commonly available locally as topical eardrops.

In our study maximum resistance was observed to Cotrimoxazole, Ampicillin-sulbactam, Azithromycin, Cefuroxime, Cefazolin, Doxycycline, Tetracycline and Cefepime (100\%) followed by high resistance to Amikacin (50\%), Ceftazidime (43.3\%) and Amoxiclav (43.3\%). The antibiotic resistance pattern in our study was in collaboration with the studies of Gulati et al16, Nandy et al ${ }^{17}$, Hiremath et al ${ }^{14}$, Saurabh et $\mathrm{al}^{18}$ and Poorey et al. ${ }^{19}$ Increased resistance to these drugs suggests that these drugs should not be considered in the treatment of CSOM cases. When the results of various workers were compared, one fact became evident that the antibiotic resistance pattern of $\mathrm{CSOM}$ has been changing from time to time. The strains of yesterday, which exhibited least resistance to Tetracyclines and Chloramphenicol no longer exhibited the old, less resistance pattern today. Previously amoxicillin /ampicillin was used frequently than quinolones for acute and chronic middle ear infections in our setup. But the present study has clearly shown a changing behaviour of microorganisms with resistance to ampicillin and amoxicillin. Amoxicillin/clavulanate combination was found to be among the least effective antibiotic not only in our study but also in other studies. ${ }^{5}$ Incidentally, this antibiotic enjoys high patronage by general duty physicians, being the most often prescribed empirical antibiotic in CSOM. Hence, its use should be abandoned in CSOM cases.

In our study, resistance to Cefepime (100\%) and Ceftazidime $(43.3 \%)$ was more compared to the resistance of Cefotaxime $(23.3 \%)$ and Ceftriaxone (23.3\%). This was in accordance with the study of Manu Chaudhary et al ${ }^{20}$ over use of Cefepime and Ceftazidime in our hospital area could be the reason for their decreased sensitivity when compared to other studies. ${ }^{21}$

Cotrimoxazole [Trimethoprim-sulfamethoxazole] is a sulfonamide antibiotic that interferes with bacterial folic acid synthesis by inhibiting dihydrofolic acid formation from paraaminobenzoic acid and by inhibiting dihydrofolic acid reduction to tetrahydrofolate. While many organisms are resistant to Cotrimoxazole, Staphylococcus aureus bear the inherent trait of resistance against this drug. Moreover, MRSA isolates are often resistant to trimethoprim-sulfamethoxazole. Cotrimoxazole resistance in our study could be attributed partly to the increased isolation rate of MRSA among Staphylococcal isolates and partly to the inherent trait of resistance against the drug borne by staphylococcus. Increased Azithromycin resistance in our study suggests a drift in the antibiotic sensitivity to Azithromycin as observed in other studies also. ${ }^{22}$

MRSA is a common pathogen in otologic diseases. The first strains of MRSA were identified in 1961.23 Since then, the proportion of nosocomial MRSA isolates has increased worldwide from $2 \%$ in 1974 to $50 \%$ in 1997.24 There has been a steady increase in the number of cases of MRSA otorrhea. ${ }^{25-30}$

For example, studies monitoring staphylococcal isolates in cases of chronic otitis media have reported MRSA incidence rates of $22.3 \%$ in Japan. ${ }^{31}$ and 25\% in Taiwan. ${ }^{28}$ In Korea, 70\% 
of $S$. aureus strains have been MRSA since the mid-1990s and it is one of the most common isolated bacteria in chronic otitis media with an incidence of about $30 \% .32$

In our study, the isolation of MRSA among Staphylococcal isolates was $68.2 \%$. The study of Swarooparani et al ${ }^{6}$ showed a $51.7 \%$ isolation of MRSA. Increased isolation of MRSA in our study suggests increased resistance to not only methicillin, but also to all $\beta$ lactams and other groups of drugs as well. When MRSA is seen in a significant number of patients, due consideration should be given to it while prescribing empirical drugs to patients with CSOM. These observations may not hold true to all areas, because bacteriology and sensitivity can change from region to region. We advocate improved hygiene, clean clothing, educational campaigns on frequent hand washing, round-the-clock urgent care and dedicated wound clinics as potential interventions to reduce the prevalence of MRSA in our hospital area. Frequent and appropriate aural cleansing and irrigation using diluted acetic acid or other solutions such as Burow's solution can be an effective measure for the medical treatment of MRSA in CSOM.

\section{CONCLUSION}

CSOM in our hospital area can be considered as a primary infection. Staphylococcus aureus is the predominant pathogen of CSOM in the dry and less humid regions. Enterococci, generally regarded as normal flora of gastrointestinal and genitourinary tract of humans is emerging as the aetiological agent in CSOM cases. High degree of resistance to Cotrimoxazole, Ampicillin-sulbactam, Azithromycin, Cefuroxime, Cefazolin, Doxycycline, Tetracycline and Cefepime was observed suggesting that these drugs should not be used for the treatment of CSOM in our hospital area. The strains of yesterday which exhibited least resistance to Tetracyclines and Chloramphenicol no longer exhibited the old resistance pattern today. While many organisms are resistant to Cotrimoxazole, Staphylococcus aureus bear the inherent trait of resistance. Though amoxiclav enjoys high patronage by general duty physicians, being the most often prescribed empirical antibiotic in CSOM it was found to be among the least effective antibiotics. Cotrimoxazole resistance in our study could also be attributed to the inherent trait of resistance exhibited by Staphylococcus aureus against this drug as well as to the increased isolation of MRSA. Sensitivity to cefepime and ceftazidime in our study was less compared to sensitivity of cefotaxime and ceftriaxone suggesting overuse of these drugs. Hence, the study recommends judicious use of these drugs. The proportion of nosocomial MRSA isolates has increased worldwide. Increased isolation of MRSA in our hospital area necessitates measures to reduce the prevalence of MRSA in our hospital area.

\section{ACKNOWLEDGEMENT}

We acknowledge our gratitude to our Institutes Research Council, our Dean and the ENT Department of AIMSR for permitting us to perform this study. We also acknowledge the efforts of the laboratory technicians of the Microbiology Department.

\section{REFERENCES}

1. Ruby N, Mohammad KF, Ruchi G, et al. Bacterial profile and antibiotic sensitivity pattern of CSOM patient in Mewat region. JEBMH 2015;2(61):9051-4.
2. Eason RJ, Harding E, Nicholson R, et al. Chronic suppurative otitis media in the Solomon Islands: a prospective, microbiological, audiometric and therapeutic survey. N Z Med J 1986;99(812):812-5.

3. Vishwanath S, Mukhopadhyay C, Prakash R, et al. Chronic suppurative otitis media: optimizing initial antibiotic therapy in a tertiary care setup. Indian J Otolaryngol Head Neck Surg 2012;64(3):285-9.

4. Asifa N, Kadri SM. Aerobic bacteriology of chronic suppurative otitis media: a hospital based study. Int J Res Med Sci 2014;2(4):1521-5.

5. Orji FT, Dike BO. Observations on the current bacteriological profile of chronic suppurative otitis media in south eastern Nigeria. Ann Med Health Sci Res 2015;5(2):124-8.

6. Swarooprani NB, Kardesai SG, Metgud SC. Aerobic bacteriological study of chronic suppurative otitis media with reference to MRSA and ESBL. SMU Medical Journal 2014;1(1)120-8.

7. Kim SH, Kim MG, Kim SS, et al. Change in detection rate of methicillin-resistant staphylococcus aureus and pseudomonas aeruginosa and their antibiotic sensitivities in patients with chronic suppurative otitis media. J Int Adv Otol 2015;11(2):151-6.

8. Performance standards for antimicrobial susceptibility testing. Pennsylvania, USA. Clinical and Laboratory Standard Institute 2007;1(1):M2-A9.

9. Saranya SK, Vazhavandal G, Ganesh VB, et al. Bacteriological and mycological profile of chronic suppurative otitis media in a tertiary teaching hospital, Trichy, Tamilnadu. International Journal of Pharmaceutical Science Invention 2015;4(1):13-9.

10. Nwabuisi C, Ologe FE. Pathogenic agents of chronic suppurative otitis media in Ilorin, Nigeria. East African Medical Journal 2002;79(4):202-5.

11. Mansoor T, Musani MA, Khalid G, et al. Pseudomonas aeruginosa in chronic suppurative otitis media: sensitivity spectrum against various antibiotics in Karachi. J Ayub Med Coll Abbottabad 2009;21(2):120-3.

12. Nagaraja B, Zahir F, Rao PN. Microbiological study of CSOM at KIMS-Amalapuram. JEMBH 2016;3(1):46-8.

13. Vaishnavi DG. Aerobic bacteriology of chronic suppurative otitis media. A hospital based cross sectional study. IJSR 2015;4(6):607-9.

14. Hiremath SL, Kanta RC, Yeshwanathrao M, et al. Aerobic bacterial isolates of CSOM and their antibiotic sensitivity pattern. The Indian Practitioner 2001;54(7):486-9.

15. Loy AH, Tan AL, Lu PK. Microbiology of chronic suppurative otitis media in Singapore. Singapore Med J 2002;43(6):296-9.

16. Gulati SK. Investigative profile of patients of CSOM. Indian Journal of Otology 1997;3(2):59-62.

17. Nandy A, Mallya PS, Sivaranjan KC. Chronic suppurative otitis media a bacteriological study. Indian Journal of Otolaryngology 1991;43(3):136-8.

18. Saurabh V, Pratima G. Bacteriological study of CSOM. Indian Journal Otology 1999;5(2):87-91.

19. Poorey VK, Iyer A. Study of bacterial flora in CSOM and its clinical significance. Indian Journal Otolaryngol Head Neck Surg 2002;54(2):91-5. 
20. Manu C, Anurag P. Rising antimicrobial resistance of pseudomonas aeruginosa isolated from clinical specimens in India. J Proteomics Bioinform 2013;6(1): 5-9

21. Ahmed S. Antibiotics in chronic suppurative otitis media: a bacteriologic study. EJENTAS 2013;14(3):191-4.

22. Suhail AP, Shakeel MW, Naveed A, et al. Drift in the bacteriology of chronic suppurative otitis media and methicillin-resistant staphylococcus aureus as an emerging pathogen: an experience. International Journal Medical Science and Public Health 2016;5(4):671-7.

23. Jevons MP. Celbenin resistant staphylococci. BMJ 1961;1 (5219):124-5.

24. Lowy FD. Staphylococcus aureus infections. N Engl J Med 1998;339(8):520-32.

25. Suh HK, Jeon YH, Song JS, et al. A molecular epidemiologic study of methicillin-resistant staphylococcus aureus infection in patients undergoing middle ear surgery. Eur Arch Otorhinolaryngol 1998;255(7):347-51.

26. Santos F, Mankarious LA, Eavey RD. MRSA pediatric otitis. Arch Otolaryngol Head Neck Surg 2000;126(11): 1383-5.
27. Hartnick CJ, Shott S, Willging JP, et al. Methicillinresistant staphylococcus aureus otorrhea after tympanostomy tube placement an emerging concern. Arch Otolaryngol Head Neck Surg 2000;126(12):1440-3.

28. Hwang JH, Tsai HY, Liu TC. Community-acquired methicillin resistant staphylococcus aureus infections in discharging ears. Acta Otolaryngol 2002;122(8):27-30.

29. Jang $\mathrm{CH}$, Song $\mathrm{CH}$, Wang PC. Topical vancomycin for chronic suppurative otitis media with methicillinresistant staphylococcus aureus otorrhoea. J Laryngol Otol 2004;118(8):645-57.

30. Hunt A, Robb PJ. Successful treatment of MRSA otorrhoea: a case report. J Laryngol Otol 2006;120(1): 63-4.

31. Furukawa M, Minekawa A, Haruyama T, et al. Clinical effectiveness of ototopical application of mupirocin ointment in methicillin-resistant staphylococcus aureus otorrhea. Otol Neurotol 2008;29(5):676-8.

32. Park DC, Lee SK, Cha CI, et al. Antimicrobial resistance of staphylococcus from otorrhea in chronic suppurative otitis media and comparison with results of all isolated staphylococci. Eur J Clin Microbiol Infect Dis 2008;27 (7):571-7. 